\title{
Regulating the Urban Commons: A Romanian Case Study of Improving Building Facades
}

\author{
Anamaria Vrabie \\ Bucharest University of Economic Studies, Department of Economics and \\ Economic Policies, Research Center for Productivity, Romania \\ vrabie.anamaria@gmail.com \\ https://orcid.org/0000-0002-5474-2013 \\ Rodica Ianole-Călin \\ University of Bucharest, Faculty of Business and Administration, Center for \\ Applied Behavioral Economics, Romania \\ rodica.ianole@faa.unibuc.ro \\ https://orcid.org/0000-0001-8931-1179
}

Received: 11. 8. 2020

Accepted: 18. 11.2020

\section{ABSTRACT}

This paper examines the effect of build environment regulations for facades emergency repairs and embellishment, as implemented by the city of Cluj-Napoca, the second largest municipality in Romania. The scope was to identify to what extent the over taxation measure was efficient in generating compliant behaviour and what secondary effects it may have generated in people's attitude towards the local authorities. We conducted structured interviews with 25 homeowners targeted by the policy. The qualitative analysis uncovers structural issues on how the policy was implemented and communicated to the population. It further acknowledges difficulties in managing mixed property and collective actions. We interpret the findings as a first step towards building a more comprehensive research framework focused also on included behavioural insights, as captured by our recommendations. Namely, they illustrate that homeowners were critical about the measure, both in its rationale and its implementation, and were unable to act upon a cost-benefit analysis given the ambiguous available information. The findings further acknowledge difficulties in managing mixed property and collective actions, but they also hint favourably towards the role of peer effects, expressed here as compliant neighbours' behaviour. We interpret the results of this exploratory case study as a first step towards building a more comprehensive approach to serve as a toolkit in examining the development of innovative local policies in post-communist environments, through a combined research framework including also the significant contribution of behavioural insights, next to the traditional rational actor theories. Naturally, the usual limitations of the method also apply to our study, in the sense 
of non-generalizable conclusions. This fuels up the need for further research on similar regional and urban challenges in an extended multiplecase study scheme.

Keywords: compliant behaviour, building facades, regulation, policy design, behavioural insights

JEL: H41

\section{Introduction}

The modern urban environment poses less and less doubts about the need of land and building use regulation policies. Instead, what it does is to raise a lot of questions about the amount and intensity of such regulations, along with many challenges in estimating its real, and often confounding, effects on welfare (Turner et al., 2014). The increased level of adversity in both economic and political conditions generated by the 2008's crisis has exacerbated planning problems, especially in areas without sound urban policies, like Southern and Eastern Europe (Ponzini, 2016). For the case of housing, the region stands out by a much higher rate of homeowners, ranging from approximately $96 \%$ in Romania, 90\% in Slovakia, Croatia and Lithuania, to roughly $80 \%$ in Bulgaria, Estonia and Czech Republic, by comparison to an average of 50-60\% in Western Europe (Eurostat, 2017; Tsenkova, 2017). Partially, this is a result of the post-communist governmental endowments introduced in the early transition phase (Druica et al., 2014) as part of the housing privatization reform (PichlerMilanovich, 2001). However, there is reason to include in the explanation the expansion of consumerist orientations (Druica et al., 2010) and social values associating real estate with wealth, expressed also through the proliferation of owner-build housing in rural and suburban areas (Soaita, 2013). All these factors kept homeownership rates at a very high level even some decades after transitioning to a market economy. Paradoxically, these rates coexist with overcrowded households (Chelcea and Druta, 2016), a very low percentage of build-up area (Pontarollo and Serpieri, 2020), respectively with evidence illustrating a significant lack of action regarding home improvement from the part of homeowners, either flat-owner or self-builders (Soaita, 2015).

Progressing towards the public policy responses and the role of regulatory control, it is noteworthy to start by mentioning the detailed account offered by Peter Marcuse (1996) on the differences between property, property rights and ownership, as the concepts are perceived in Eastern (specifically in light of the soviet model) and Western Europe. He emphasizes the permanent tension between the inclination to apply free market rules and the inclination to apply public control, following the assumption that urban development should firstly serve a collective interest. In the attempt to favour more the new model but without being aware of the remaining old habits, Romania is faced nowadays with a situation of degrading facades - both for houses and flats - and a lack of rule of law able to induce cooperation between the state 
and the individuals in solving this issue for the benefit of all actors (Valsan et al., 2015; Luca, 2009): "a crisis of legitimacy regarding the planning by the lack of consistent specific measures for the city development" (Suditu et al., 2014, p. 135). Ojamäe and Paadam (2015) present a similar case for the process of flat owners' collective renovation in Estonia. They highlight trust, and subsequently communication, as significant variables for success, with emphasis on the capacity of the public sector to generate and sustain such trust between the involved parties. Another noteworthy case study belongs to Mandic and Clapham (1996) and it depicts the structure and meaning of home ownership in Slovenia, before and after the country's transition to a market economy. While the final results mirror the statistics of the region, the analysis reveals more details for what constitutes the foundation for housing preferences, from the overwhelming need for shelter (as opposed to a simple desire for possession) to strategic thinking in exploiting inflation and economic reforms. All in all, the literature niche devoted to regional initiatives focused on modernizing multi-apartment buildings is an emergent one (Andrews and Sendi, 2001; Bieksa et al., 2011; Korppoo and Korobova, 2012). However, the lack of reliable and comparable data is a significant barrier for the development of more evidence-based policies for this segment.

Our paper attempts to address this gap by illustrating the premises of public innovation through a particular intervention designed by the Romanian municipality of Cluj-Napoca with the purpose of acting as an enforcement mechanism to avoid public casualties and negative city image: an increased level of taxation for buildings that are in a derelict state and pose threats to public safety. We employed a qualitative approach, collecting data in the period July-September 2017 through physical structured interviews with 25 homeowners that fall under the scope of the experimental measure. We discuss the findings having as background the main theories consecrated to the understanding of compliance behaviour: the rational model of crime, social norms theory and the more recent behavioural insights. We complement the analysis with a set of recommendations for achieving behaviour change in a non-regulatory and non-fiscal manner, in the spirit of the current applications of behavioural economics to policy design.

\section{Understanding compliance behaviour}

\subsection{Classical models}

Becker's seminal paper of the rational model of crime (1968) stands out as a reference point for applying standard economic thinking to any type of decision-making process, including crimes. His framework postulates that if the estimated benefits of not abiding to the law action are bigger than the estimated costs (computed as the sanctions weighted by the probability of getting caught), it is economically rational for the individual to engage in the action. Thus, the standard economic response to such behaviour is none other than increasing the perceived costs - the threat of sanctions. 
While the model has a strong theoretical appeal, the match with reality reveals a lot of prediction errors. The theory of planned behaviour (Ajzen and Fishbein, 1970) constitutes a refinement of rational decision-making models, emphasizing the role played by three majors elements: attitudes, subjective norms and perceived behavioural control. It is still considered a classical approach, where attitude is somewhat the equivalent of utility (by analogy with rational choice), but nonetheless it opens up to two more comprehensive factors. For example, in an analysis aimed at identifying compliance drivers for the case of urban water restrictions in Australian cities, Cooper (2017) highlights the strong and positive influence of perceived behavioural control, which is defined as an individual's understanding of their capacity to achieve a behaviour (d'Astous et al., 2005). Following this result, the recommendation set clearly suggests a reconfiguration of policies in the sense of supporting households to meet regulatory criteria, which is to increase their perceived behavioural control on the issue at hand.

This leads us to a number of alternative explanations, integrating next to the pure economic factors a larger spectrum of psychological and sociological variables. Sutinen and Kuperan (1999) propose a model of compliance including variables like morality, on the side of intrinsic motivators, and social influence, as an extrinsic motivator. Naturally, there are some difficulties in measuring moral development, personal values or perceived legitimacy of an intervention, but there is increasing empirical evidence for a positive impact in understanding generated by this class of models. Similar improvements are captured through the grasp of social norms and their function of signalling what may constitute an appropriate behaviour in a compliance situation (Dolan et al., 2012).

\subsection{Behavioural interventions}

A step further in the compliance philosophy is brought by the heterogeneous class of behavioural models proposing explanations rooted in cognitive biases (overconfidence, sunk costs, myopic time preferences etc.) or simply in new perspectives about human behaviour, like the acceptance of social preferences (e.g. people care about themselves and also about others). If the standard economic view is linked to deterrence and enforcement policies, the behavioural one is associated to growing evidence of behavioural interventions around the world (Ly and Soman, 2013), in areas such as employment (Hossain and List, 2012; Fryer et al., 2012), consumer policy (Bertrand et al., 2010; Goda and Manchester, 2013), health (Ianole, 2016; Volpp et al., 2009; Milkman et al., 2011), taxation (Torgler, 2004), environment (Shogren, 2012) or transport (Garcia-Sierra et al., 2015).

These interventions mostly employ nudging, under the choice architecture movement (Szaszi et al., 2017), along the more classical strategies of behavioural change (e.g. positive and negative incentives, persuasion, information etc.). We use as a reference point the "behaviour change interventions" taxonomy described in the 2011 Behaviour Change report of the House of Lords 
Science and Technology Select Committee, which builds of the Nuffield Ladder of Interventions (House of Lords, 2011). This framework includes three main directions: (1) regulation of the individual, (2) fiscal measures directed at the individual, and (3) non-regulatory and non-fiscal measures with relation to the individual. The first category offers procedures that reflect upon the classical models, usually either eliminating choice or restricting it. Categories (2) and (3) have in common a certain level of choice guidance and choice enablement. At one end, in category (2), there are located the traditional measures of financial disincentives (e.g. they make behaviours more costly) and financial incentives (e.g. they make behaviours financially beneficial). At the other end, category (3) progresses from non-fiscal incentives and disincentives, and persuasion, towards nudges and choice architecture initiatives: provision of information, changes to physical environment, changes to the default policy and the use of social norms and salience.

In light of different experiences of applying behavioural public policy, the current perspective (Lowenstein and Chater, 2017) highlights a shift from the somewhat standard recipe that a behavioural solution is to be considered only after the implementation of habitual tools of conventional economics. Naturally, this may be quite a natural step in approaching a problem: after understanding the context and identifying the desired behaviour change, a major challenge is to asses if the targeted processes and structures are cleared from any issues requesting standard economic interventions (Ly et al., 2013), like taxes, regulations etc. Nonetheless, this is not a logic that necessarily excludes the possibility of putting to use nudges in situations explained by traditional economic circumstances and the reverse: applying traditional economic solutions to situations explained by behavioural factors. As an illustration of the interaction between traditional strategies for behaviour change and the more recent behavioural insights, Arcos Holzinger and Biddle (2016) identify two types of behavioural models used in practice to explain tax compliance: non-expected utility models and social interaction models. The first category incorporate a wide range of behavioural biases considered relevant for the tax compliance decision (anchoring, time discounting, framing etc.), while the second refers to the links between capacity and compliance on multiple levels (trust, fairness, power etc.).

\section{Method}

\subsection{Research context}

The objective economic factor that explains an important part of the poor results in respect with housing management is clearly household's reduced affordability (Council of Europe Development Bank, 2004). Furthermore, the market conditions for housing management are not necessarily favourable to competition and the legal framework still lacks certainty, thus maintain a low appeal for investments in maintenance and renovation planning (Butler et al., 2004). This converges into the fact that a significant part of the housing stock 
in Romania is in precarious condition, due to lack of major renovations and improvements in the last few decades.

The situation is similar in Cluj-Napoca, the second most populous city in Romania, situated in the north-western part of the country and considered informally the capital of Transylvania. The case is even more salient in the historical city centre, where historical buildings are in advanced state of degradation. This poses a threat not only for the safety of building owners and tenants, but also for the general public. Building facades and roofs are an integrated part of urban commons, and have externalities on the quality of city life. While heritage and high quality architecture can have positive externalities and contribute to the authentic and pleasing aesthetic of a place, a derelict state of the building can have negative externalities risking injuries for passers-by or enhancing the risk of street criminality. Because of this, building facades and roofs are under additional public regulation, on top on the building codes they need to adhere to. National and local level public authorities have a mandate to regulate such urban commons in order to ensure public safety, heritage preservation and aesthetic coherence.

In fact, public policies connected to Romania's housing portfolio have been scarce since the country's transition to a market economy starting with 1990. As the World Bank background study on housing policies in Romania shows, new housing development is perceived as the responsibility of the private sector and private individual, with social and affordable housing stock diminishing and being neglected by national policies (World Bank Group, 2015). In part, this is a counter-reaction to the accelerated building pace of housing during communism with major state intervention, as well as the forced nationalization process of private properties that Romania experienced between 19481962. On the other hand, the same study outlines the perception that, for the existing buildings and housing dwellings, owners should care only about their private poverty and expect that a third party, preferably the public sector, takes care of any common spaces (from common access pathways, halls, gardens to roofs, basement and facades). Going beyond perception, current legislation gives powerful rights to housing owners, allowing them to effectively block a collective decision concerning their estate. For example, if a housing estate has ten owners, each owning their apartment, and nine of them agree to pay for rehabilitation works for the commons space of the estate, but one denies, then the process is blocked or discontinued. Referred by economists as an "anti-commons" problem, which describes a situation where many owners have the right to exclude others from use of a resource, resulting in the underuse of resource, it summarizes the present conundrum of Romania's housing policy (Buckley and Mathema, 2018).

Given this context, local public administration has limited policy instruments to intervene in issues concerning urban commons elements of the build environment. This is why, when a new fiscal instrument was introduced at national level in 2015, allowing local public authorities to increase taxation for build- 
ings that are in a derelict state and pose threats to public safety, it seemed a concrete tool that cities could use for their housing and fiscal public policy.

The new instrument instructed local public authorities that they could increase the building tax to up to $500 \%$ for buildings not complying with measures for being in a good maintenance state. However, it was left to each municipal authority to design the guidelines for applying this measure.

Thus, at local level, the public policy intervention allowing tax increases for abandoned or mismanaged properties corresponds to a fiscal disincentive directed to the individual. By allowing tax increases of $500 \%$ it makes the behaviour of leaving your property abandoned or mismanaged costlier. In order to design the guidance on applying the prerogatives of the fiscal code and national level policy, Cluj-Napoca municipality decided in 2016 to entrust this process to two of its departments: the local police and the local tax office. The developed methodology that resulted at local level highly relies on a subjective appraisal of a local police officer, which visits the exterior of the building. According to local council decision HCL 343/31 May 2016, the municipality can increase the building tax by $500 \%$ for homeowners who fail to comply to the recommendations of the local police for repairing their building. The policy describes the assessment process by the local police of the building state and the recommended actions that need to be taken by the homeowners. If these recommendations are not followed by the homeowners, partially or fully, the local police inform the local tax department that the building tax needs to be increased starting from 2017 fiscal year.

The local police officer hand-fills an observation sheet naming the elements of the building that seem from her or his point of view in need of repairs. Depending on the element type, the methodology describes how the local police officer should assign a score from 1 (decent condition) to 5 (bad condition) or sometimes from a scale of 1 (decent condition) to 10 (very bad condition). For example, the roof cover can get 2 points if it is partially missing and maximum $10 \%$ of its surface is damaged and 10 points if $30 \%$ of the total surface is degraded and needs total replacement. If a building gets an overall score of 25 points or higher, it is deemed in poor state and the owners are issued the subpoena. After 6 months, a police officer checks again whether any improvements have been done in the building state and the overall score can be lowered under 25. If this is not the case, the police officer makes the final recommendation to the local tax office to increase the building tax.

In 2016, the local police identified 56 buildings in the city centre area and sent 1543 subpoenas to the homeowners to consider their recommendations for building repairs. Only 525 subpoenas were actually successfully delivered, the rest either returned by post or were rejected by the homeowners. 85 homeowners filled complaints to the Cluj-Napoca municipality for abusive regulation and impossibility of compliance, and 3 litigations were started. By the end of 2016, none of the targeted buildings by the subpoenas had followed complete retrofitting, with only 3 building undergoing emergency repairs of their facades. As a result, by the end of 2016, 53 buildings comprising a total 
of 693 apartments had their building tax increased by 500\%. In the end, after applying certain tax exemption cases for building owned by public entities, veterans, religious cults etc., 528 physical and judicial persons had their property tax increase by $500 \%$. Depending on their surface and location, the new increase property tax ranged in 2016 between 35 to 3117 euros per year. Considering that the average monthly income in Romania in 2016 was around 595 euros, in most cases the increased property tax was generally a significant expense for a household. However, as later discussed in the article, the foreseen expenses for rehabilitation works are also high when compared to household's financial capacity.

\subsection{Research design}

Our initial endeavour was to work under a quantitative framework and to proceed by the means of a survey measuring the objective impact of the property-tax increase for the uncared-for buildings in the central area of ClujNapoca municipality The measure was not only stipulated in the official legal framework but the households received notifications from the Inspection and Control Department of the Cluj-Napoca Local Police However, as we have progressed in understanding the sensitivity of the topic and the narrow target group of the experimental extra-taxation measure, we decided to shift to a qualitative design and to build up a more flexible interview structure: "qualitative data tells what is happening and how and why, whereas quantitative data would indicate how much of each thing is happening" (Sunikka-Blank and Galvin, 2016). In consequence, we focused on understanding the decision to carry on, or not, maintenance works for rehabilitating the building or simply for keeping it in a good shape. This objective also mirrors contemporary recommendations for public administration research to elaborate more on the use of qualitative tradition with the aspiration to cultivate the interaction between researchers and practitioners (Ospina et al., 2017; Ashworth et al, 2019). In the context of the measure framed as an increased tax, conducting/ not conducting maintenance work was our analogy case of compliance/noncompliance behaviour.

The general structure of the interview is presented in table 1 but it is essential to highlight that it served as a reference point. Namely, the interviews were semi-structured and participants were given the freedom to describe their experiences, both with the building and with the public administration, providing a more in-depth grasp of each case. 
1. Please describe why you think you have received the summon for the Inspection and Control Department of the Cluj-Napoca Local Police.

2. Have you performed any building maintenance/support works as a result of being summoned by the Inspection and Control Department of the Cluj-Napoca Local Police? (yes/no)

3. What factors determined your previous decision?

- thinking of the benefits/costs associated to this action

- thinking of the potential punishment associated to the lack of action (over-taxation)

- the neighbours' behaviour or the behaviour of other individuals facing a similar situation

- the belief that this action is good for the community (avoiding accidents for passing people, maintaining a good image of the city)

- the belief that this action is not good for the community

4. (if applicable) To what degree, do you think you'll maintain the decision of not making maintenance works next year?

5. (if applicable) To what degree, do you think you'll be sanctioned for the decision of not making maintenance works next year?

Please use a scale from 0 to 10 , where 0 means you are "completely unwilling" and a 10 means you are "very willing ".

6. To what degree, do you think your (street) neighbours will be sanctioned for the decision of not making maintenance works next year?

7. Please describe what support you would have needed in order to comply more easily to the summon for building maintenance?

As suggested in other studies on building care and preservation, our sample was purposive rather statistically representative (Neilsen and Pojani, 2020), respectively its size was dictated by thematic saturation (Onwuegbuzie and Leech, 2007). The 25 interviews were conducted during July-September 2017 in Cluj-Napoca in front of the buildings targeted by the public policy. Prior to arranging the interviews, we distributed, in collaboration with the Inspection and Control Department of the Cluj-Napoca Local Police, 150 leaflets in postboxes announcing the scope of this research and the time and date in the following week, when our research team would call on the owners. Each semistructured interviews had a duration of 25 to 35 minutes and the answers were recorded on an observation sheet.

We used thematic analysis, considered among the most popular qualitative approaches for unveiling patterns from interview data (Clarke et al., 2015). We scrutinized interview transcripts having in mind codes derived from the theoretical models: on one hand the mechanics of the process and objective actions, on the other hand the feelings associated, perceptions, trust, so- 
cial preferences and expectations. The analysis does not make use of direct quotes given the high level of reticence of the participants in giving consent for this specific practice. Furthermore, we adopted a realist method (Crouch and McKenzie, 2006) in analysing the data, in the sense of examining it with pre-defined research questions and not in the detached style assumed by grounded theory (Charmaz, 2006).

\section{Results and discussions}

\subsection{Thematic analysis findings}

We have identified five main recurring themes from the interviews, illustrating predominantly the lack of functionality of the existing processes and procedures. The first and most salient theme was the highly subjective process of assessment for implementing the policy. Interviews revealed the mistrust that the homeowners experience in relation with this assessment process, which also impacts their preference to a pro-social behaviour of compliance. Homeowners expressed the fact that they were able to communicate with other neighbours that failed to receive the official notice from the local police by pretending they were not at home, an experience that reinforced their belief in the subjectivity of the process of assessment. Moreover, interviewees felt distressed that the assessment process was not conducted by a specialist in civil engineering, architecture or related fields, claiming that in this way it becomes just a process of giving an opinion. Based on this, most interviewees were prone to take legal action against Cluj-Napoca Municipality.

The second discontent was that no provision of information was given to homeowners. Specifically, there was no official medium of communication that would explain the rationale of the policy or the clear steps that need to be taken for its compliance. Interviews with both homeowners and local police officers, revealed the need of additional communication, such as the municipal gazette and homeowner's meetings. The information needed ought to be connected with easy to use and transparent resources for compliance, as well as describing why such a policy is needed for avoiding public casualties, as well as concrete information about how other people have solved a similar problem.

The third issue was that compliance is depended on collective action. Each building targeted by the policy is composed by apartments privately owned, with all owners having the legal requirement to organize themselves in an owner's association. According to the national legislation regulating homeowner's associations, only when the majority of owners agree on building repairs, these can be implemented. Thus, any major decision concerning the entire building is subject to a complex, and oftentimes long, collective action process. Our interviews revealed several cases where a minority of owners wanted to comply with the recommendations for retrofitting the building and were also willing to pay of all the expenses, but they encountered resistance from one fellow neighbour. In such cases, a preference for pro-social behaviour was actually discouraged by the policies in place. 
Closely linked to the previous factor, there were also mixed property issues resulting in a case of double standards for enforcing the policy. Several buildings targeted by the policy were mixed-property ones, with a share of apartments owned by entities that are tax exempt (public entities, veterans, religious cults etc.). Thus, these owners do not have any incentive to comply, and in some cases they are the ones from the homeowner's association failing to support a collective decision. Also, in some cases, depending on the legal status, they cannot advance financial resources for paying for the necessary retrofitting works. In return, they can only contribute to these expenses after they have already been completed.

Last, in some cases, the sanctions imposed were not higher than expected benefits. There is a case-by-case approach on the relative cost-benefit ratio between payment of the increased tax and payment of retrofitting costs. The baseline of calculating the increased $500 \%$ tax varies significantly, depending on the materials and location of the building. On the other hand, depending on the complexity of the necessary retrofitting works, the related costs can sometimes overweigh the payment of an increased tax even for a period of 10 years.

\subsection{Proposals of improvement of the policy design at local level using non-regulatory and non-fiscal measures}

Based on the information collected during the interviews with owners and on the compliance statistics communicated by Cluj-Napoca municipality, we looked on several complementary interventions that might be considered to accompany the fiscal disincentive already in place.

Persuasion. A possible policy intervention would be a public awareness campaign for all Cluj-Napoca residents to convey that immediate action is needed for retrofitting the buildings. In this way, all residents would become informed about the issue and actions needed for addressing it. The public awareness campaign should also be explicit on how the issue is a public interest one, with potential negative effects on all city residents, in case of no action. It should also have a specific call to action, in order to effectively persuade homeowners to retrofit their buildings. Possible calls to actions would be for homeowners to contact immediately a dedicated taskforce from the municipality or access general helpline or app through which residents can signal unsafe building. The campaign would not disclose personal data of inhabitants, thus being in conflict with the European Union regulations on privacy (also known as GDPR act). It would rather enable general awareness of the issue around Cluj-Napoca residents, as well as access to a helpline or other personalized support for residents that self-identify as owners or inhabitants in derelict or unsafe buildings.

Provision of information. Finding the necessary information about the appliance of increased taxes and ways to comply with the retrofitting requirements should be easy and accessible for every homeowner. Due to the diversity of the demographic profile of homeowners and renters living in the buildings, leaflets should be most effective medium, reaching both a digital 
and non-digital generation. The leaflets and posters should also contain information on the impact of the tax increase beyond the current year. In this way, affected homeowners would be empowered to assess the full costs of non-compliance, rather than just focusing on a simple cost-benefit analysis of the current year, as most of the interviewees were considering. Similarly, there would be no disclosure of personal data of inhabitants, rather creating the mechanisms that residents self-identify as a potential beneficiary of the information contained by the leaflets, posters and other mass media outlets.

Change in physical environment. As buildings targeted by this local policy are dangerous for the general public, there should be visible displays that would make this reality explicit for every passer-by. Because the local public authority can impose and also operate changes in the facades of the building, an example of an intervention could be a mesh (textile cloth used for advertising on build environment) covering partially or totally the façade. On the mesh there should be a clear message about the derelict situation of the building, the implication for public safety and a reference that action is needed from owners. A tougher version of these interventions could also include disclosing the names of the owners that have failed to take action/comply to the local policy. Such a disclosure, although controversial, could tackle false perceptions that build environment is under the jurisdiction of the public authority, as some of the interviewees hinted. Also, it could use social norms to adjust perceptions on the number of owners willing to comply with the local public policy, in comparison to the non-compliers. This design element could prove particularly efficient for multi-owner buildings, where a consensus for covering the retrofitting costs was blocked only by a minority of owners.

Use of social norms and salience. Proactively tackling public perceptions of compliance and non-compliance can serve as a powerful tool for the collective action needed to retrofit derelict buildings. Each owner could receive a personalized letter in the same time she receives the notice that the building needs to undergo improvement work or risk a tax increase, providing information about actions of municipal owned building and their compliance. The letter could also provide information about neighbours willing to cover costs for retrofitting or information on how their buildings tax rates compared to the rest of the building tax from building on the street. In this way, owners are encouraged to change their reference point.

\section{Conclusion}

The effectiveness of public policies often depends on how people react to it and the extent to which people's real behaviour is taken into account when designing policies. The main objective of the present survey was to identify how Cluj-Napoca's homeowners of buildings evaluated to be in a derelict state and posing threats to public safety, have reacted to the new penalty regulation imposed by the municipality. Beyond observing their engagement behavior in a binary manner, the aim was to have a sense of their perception on the entire process and to identify critical points for improving future simi- 
lar approaches. Our results show that, generally speaking, the interviewed homeowners were sensitive and critical to the assessment procedures underlying the taxation measure. The economic costs and benefits of their participation in building care were rather ambiguous given the strong asymmetry of information and weak communication with the public authorities. Thus, understanding the motivation for compliance in this particular case also confirms the limits of the rational actor approach, as suggested in the literature review section, revealing the stringent need to build and strengthen trust and social capital. This aspect is reinforced by recent research pointing to the fact that the perceptions of a weak state capacity, respectively of lack of distributive justice, are factors that enhance the level of tolerance towards tax evasion and informal economy practices (Vâlsan et al., 2020). More so, peer effects expressed as neighbours' behaviour have been shown to positively impact tax compliance (Alm et al, 2017), setting an important precedent for even more visible changes, like in the case of improving building facades.

Given that achieving a sustainable building stock and a positive city image in Cluj-Napoca, and in the rest of the country, significantly depends on the active engagement of the homeowners in building care, the findings of this case study advance valuable ideas for rethinking local policies in the arena of building management and maintenance in the city.

The use of a behavioural approach can point out directly to the critical aspects that need immediate reconsideration in order to further consider pro-social incentives mechanisms for designing programs related to the delivery of public services and urban policy. Our study manages to highlight best the difficulty of applying a behavioural research framework in the very grey case of a post-communist society (lanole-Calin et al., 2017). At first glance, a superficial conclusion can be drawn: that behavioural insights are not appropriate for the very pragmatic problems of such societies. We believe this to be false and counterproductive. Difficulties in implementing alternative approaches are clearly hard to ignore but the mere exposure to them generates the start of a changing process that has an evidence-based nature. Furthermore, beyond cultural and institutional determinants, the success of behavioural public policy interventions is also partially deterred by the poor quality reporting of interventions and methods in some areas (Cotterill et al., 2020). On the positive side, the synergy achieved by using behavioral insights techniques in the framework of public innovation laboratories, as it is also the incipient position of the Urban Innovation Unit in Cluj-Napoca (Vrabie and Ianole-Calin, 2020), is a growing trend with promising outcomes. 


\section{References}

A. M. (2013). Romanian suburban housing: Home improvement through ownerbuilding. Urban Studies, 50(10), pp. 2084-2101.

Ajzen, I. and Fishbein, M. (1970). The prediction of behavior from attitudinal and normative variables. Journal of experimental social Psychology, 6(4), pp. 466-487.

Alm, J., Bloomquist, K. M. and McKee, M. (2017). When you know your neighbour pays taxes: Information, peer effects and tax compliance. Fiscal Studies, 38(4), pp. 587-613.

Arcos Holzinger, L. and Biddle, N. (2016). Behavioural insights of tax compliance: An overview of recent conceptual and empirical approaches. Tax and Transfer Policy Institute-Working Paper, 8.

Andrews, K. D. and Sendi, R. (2001). Large housing estates in Slovenia: a framework for renewal. International Journal of Housing Policy, 1(2), pp. 233-255.

Ashworth, R. E., McDermott, A. M. and Currie, G. (2019). Theorizing from qualitative research in public administration: Plurality through a combination of rigor and richness. Journal of public administration research and theory, 29(2), pp. 318-333.

Bertrand, M. et al. (2010). What's advertising content worth? Evidence from a consumer credit marketing field experiment. The Quarterly Journal of Economics, 125(1), pp. 263-306.

Biekša, D. et al. (2011). Energy efficiency challenges in multi-apartment building renovation in Lithuania. Journal of Civil Engineering and Management, 17(4), pp. 467-475.

Buckley, R. and Mathema, A. (2018) 'Housing privatization in Romania: An Anti-commons tragedy?' Economics of Transition, 26(1), pp. 127-145. DOI: 10.1111/ecot.12140.

Butler, S. et al. (2004). Real Estate Finance and the Real Estate Market in Bosnia: Unlocking Capital for Development. Washington DC: The Urban Institute.

Charmaz, K. (2006). Constructing grounded theory: A practical guide through qualitative analysis. Sage.

Chelcea, L. and Druţă, O. (2016). Zombie socialism and the rise of neoliberalism in post-socialist Central and Eastern Europe. Eurasian Geography and Economics, 57(4-5), pp. 521-544.

Clarke, V., Braun, V. and Hayfield, N. (2015). Thematic analysis. Qualitative psychology: A practical guide to research methods, pp. 222-248.

Cooper, B. (2017). What drives compliance? An application of the theory of planned behaviour to urban water restrictions using structural equation modelling. Applied Economics, 49(14), pp. 1426-1439.

Council of Europe Development Council and the World Bank. (2004): Housing in South Eastern Europe; Solving the Problem, Paris, March.

Cotterill, S., John, P. and Johnston, M. (2020). How can better monitoring, reporting and evaluation standards advance behavioural public policy? Policy and Politics.

Crouch, M. and McKenzie, H. (2006). The logic of small samples in interviewbased qualitative research. Social science information, 45(4), pp. 483-499.

D'Astous, A., Colbert, F., and Montpetit, D. (2005). Music piracy on the web-how effective are anti-piracy arguments? Evidence from the theory of planned behaviour. Journal of Consumer Policy, 28(3), pp. 289-310. 
Dolan, P. et al. (2012). Influencing behaviour: The mindspace way. Journal of Economic Psychology, 33(1), pp. 264-277.

Druica, E., Valsan, C. and lanole, R. (2015). Residential Real Estate in Europe: An Exploration of Common Risk Factors. Review of Economic Perspectives, 15(4), pp. 413-429.

Druica, E., Cornescu, V. and lanole, R. (2010). Consumerism and hyperconsumerism in the Romanian society. Global Business and Management Research: An International Journal, 2(4), pp. 386-402.

Fryer Jr, R. G. et al. (2012). Enhancing the efficacy of teacher incentives through loss aversion: A field experiment (No. w18237). National Bureau of Economic Research.

Garcia-Sierra, M., van den Bergh, J. C. and Miralles-Guasch, C. (2015). Behavioural economics, travel behaviour and environmental-transport policy. Transportation Research Part D: Transport and Environment, 41, pp. 288-305.

Goda, G. S. and Manchester, C. F. (2013). Incorporating employee heterogeneity into default rules for retirement plan selection. Journal of Human Resources, 48(1), pp. 198-235.

Hossain, T. and List, J. A. (2012). The behavioralist visits the factory: Increasing productivity using simple framing manipulations. Management Science, 58(12), pp. 2151-2167.

Korppoo, A. and Korobova, N. (2012). Modernizing residential heating in Russia: End-use practices, legal developments, and future prospects. Energy Policy, 42, pp. 213-220.

Ianole, R. (Ed.). (2016). Applied Behavioral Economics Research and Trends. IGI Global.

Ianole-Călin, R., Vâlsan, C. and Druică, E. (2017). The Many Shades of the Grey Economy in Romania. The Informal Economy: Exploring Drivers and Practices, pp. 25-40.

Ly, K. et al. (2013). A practitioner's guide to nudging. Rotman School of Management Working Paper, (2609347).

Ly, K. and Soman, D. (2013). Nudging around the world. Rotman School of Management: University of Toronto.

Loewenstein, G. and Chater, N. (2017). Putting nudges in perspective. Behavioural Public Policy, 1(1), pp. 26-53.

Luca, O. (2009). Urban regeneration process in Romania. Theoretical and Empirical Researches in Urban Management, 4(10), pp. 136-143.

Mandic, S. and Clapham, D. (1996). The meaning of home ownership in the transition from socialism: the example of Slovenia. Urban Studies, 33(1), pp. 83-97.

Marcuse, P. (1996). Privatization and its discontents: Property rights in land and housing in the transition in Eastern Europe. Cities after socialism: Urban and regional change and conflict in post-socialist societies, pp. 119-191.

Milkman, K. L. et al. (2011). Using implementation intentions prompts to enhance influenza vaccination rates. Proceedings of the National Academy of Sciences, 108(26), pp. 10415-10420.

Neilsen, V. and Pojani, D. (2020). Perspectives on built heritage preservation: a study of Queenslander homeowners in Brisbane, Australia. Journal of Housing and the Built Environment, pp. 1-23. 
Ojamäe, L. and Paadam, K. (2015). The phenomenon of trust in flat owners' collective renovation strategies in Estonia. Studies of Transition States and Societies, 7(2).

Onwuegbuzie, A. J. and Leech, N. L. (2007). A call for qualitative power analyses. Quality and Quantity, 41(1), pp. 105-121.

Ospina, S. M., Esteve, M. and Lee, S. (2018). Assessing qualitative studies in public administration research. Public Administration Review, 78(4), pp. 593-605.

Pichler-Milanovich, N. (2001). Urban housing markets in Central and Eastern Europe: convergence, divergence or policy'collapse'. European Journal of Housing Policy, 1(2), pp. 145-187.

Pontarollo, N. and Serpieri, C. (2020). Testing the Environmental Kuznets Curve hypothesis on land use: The case of Romania. Land Use Policy, 97, p. 104695.

Ponzini, D. (2016). Introduction: crisis and renewal of contemporary urban planning. European Planning Studies, 24(7), pp. 1237-1245.

Shogren, J. (2012). Behavioural economics and environmental incentives. OECD Environment Working Papers, (49), 0_1.

Soaita, A. M. (2015). The meaning of home in Romania: views from urban owneroccupiers. Journal of Housing and the Built Environment, 30(1), pp. 69-85.

Suditu, B. et al. (2014). Suburban landscapes in Romania: From 'forting-up'to 'informal-up'and limits of public action. European Journal of Science and Theology, 10(5), pp. 125-138.

Sunikka-Blank, M. and Galvin, R. (2016). Irrational homeowners? How aesthetics and heritage values influence thermal retrofit decisions in the United Kingdom. Energy Research and Social Science, 11, pp. 97-108.

Szaszi, B. et al. (2017). A Systematic Scoping Review of the Choice Architecture Movement: Toward Understanding When and Why Nudges Work. Journal of Behavioral Decision Making.

Sutinen, J. G. and Kuperan, K. (1999). A socio-economic theory of regulatory compliance. International journal of social economics, 26(1/2/3), pp. 174-193.

Torgler, B. (2004). Moral suasion: An alternative tax policy strategy? Evidence from a controlled field experiment in Switzerland. Economics of Governance, 5(3), pp. 235-253.

Tsenkova, S. (2017). Housing change in East and Central Europe: integration or fragmentation? Routledge.

Turner, M. A., Haughwout, A. and Van Der Klaauw, W. (2014). Land use regulation and welfare. Econometrica, 82(4), pp. 1341-1403.

Valsan, C., Druica, E. and lanole, R. (2015). From neo-Stalinism to sluggish markets: Transition in Romania. In Strategies towards the new sustainability paradigm (pp. 35-48). Springer, Cham.

Vâlsan, C., Druică, E. and Ianole-Călin, R. (2020). State Capacity and Tolerance towards Tax Evasion: First Evidence from Romania. Administrative Sciences, 10(2), p. 33.

Volpp, K. G. et al. (2009). A randomized, controlled trial of financial incentives for smoking cessation. New England Journal of Medicine, 360(7), pp. 699-709.

Vrabie, A. and Ianole-Călin, R. (2020). A Comparative Analysis of Municipal Public Innovation: Evidence from Romania and United States. Journal of Open Innovation: Technology, Market, and Complexity, 6(4), p. 112.

World Bank Group. (2015). Housing in Romania. At <http://documents1.worldbank. org/curated/en/552171468585744221/pdf/106856-REVISED-WP-Romania HousingRASOutputFinalHousingAssessment-PUBLIC.pdf.Soaita> accessed 3 November 2020. 